\title{
OBITUARY
}

\section{In memoriam: Goran Hedenstierna}

\author{
Luciano Gattinoni ${ }^{1}$ and Massimo Antonelli ${ }^{2^{*}}$ (B)
}

C 2021 Springer-Verlag GmbH Germany, part of Springer Nature

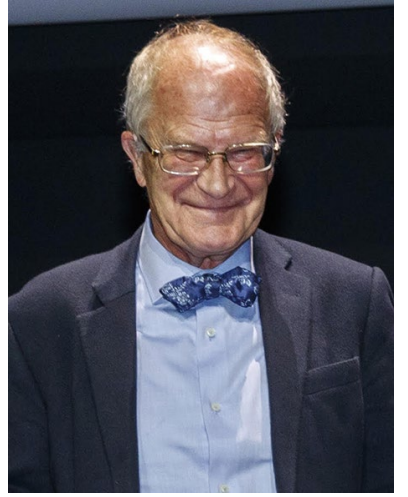

There are some things that you want never to have to think about, and some words you would like never to have to write, especially when they concern someone who has been, for 40 years, not just a colleague but also a dear friend. Goran Hedenstierna passed away on July 12, calm and mindful, as was his way.

Now is not the time to run through his scientific achievements; after all, reconstructing his career, successes and awards from entries in PubMed, Scopus and other similar sources, would be a dry exercise. What matters here is to underline the uniqueness of Goran the person, which derived from his various intrinsic qualities: intelligence, curiosity, humanity and a great capacity for the work he did. A uniqueness also born of his academic title: clinical physiologist. Put simply, clinical physiology is the translation of physiology techniques and functional anatomy to the clinic. How many clinical physiologists do we have nowadays? Not too many, with the difference that Goran devoted his entire professional journey to the role.

Goran was the first to use computer tomography technology to quantitate lung "pathoanatomy", thereby greatly contributing to our understanding of lung volumes and mechanics; he fully described the anatomo-functional distribution of ventilation, perfusion and gas exchange.
Brilliant people often guard their knowledge and expertise jealously, reluctant share their science with colleagues or to teach it to the upcoming generations. In this regard, too, Goran was a splendid exception. Indeed, years before the publication of important papers, he would willingly share his discoveries, certainties and doubts with many of us.

He was a wonderful tutor as well. For dozens of young scientists from Europe, Asia and America, Goran was a valuable and enthusiastic mentor, not merely a professional point of reference. His workplace, his home and his boat were, for Goran, all part of a single space, where curiosity, research and friendship constantly co-existed.

He was an inspired "magister" - a master and a guide for so many young fellows. From 2007 to 2013, he was a fantastic deputy editor of Intensive Care Medicine, ESICM's official journal. He approached the role with wisdom, competence and kindness. He always had immense respect for the journal's authors and contributors, especially the younger ones. Accordingly, his comments were always constructive, and his suggestions useful, made with the aim of improving the submitted manuscripts for the benefit of science.

The pain of his loss is acute, but we can take comfort from the fact that the memory that will remain is that of a man who lived a full and precious life, for himself, his family and the entire academic community.

Anyone looking at a quantitative CT scan, evaluating respiratory mechanics or assessing gas exchange should pause for a moment and remember the debt that, directly or indirectly, we owe Goran Hedenstierna. ${ }^{*}$ Correspondence: massimo.antonelli@unicatt.it
${ }^{2}$ Department of Anesthesiology and Intensive Care Medicine, Catholic
University of Rome, Rome, Italy

Full author information is available at the end of the article 


\section{Author details}

Department of Anesthesiology, University of Gottingen, Gottingen, Germany.

${ }^{2}$ Department of Anesthesiology and Intensive Care Medicine, Catholic University of Rome, Rome, Italy.

\section{Publisher's Note}

Springer Nature remains neutral with regard to jurisdictional claims in published maps and institutional affiliations.
Received: 20 July 2021 Accepted: 20 July 2021

Published online: 12 August 2021 